\title{
Laparoscopic central pancreatectomy for solid pseudopapillary tumors of the pancreas: our experience with ten cases
}

\author{
Xue-Min Chen ${ }^{*+}$, Yue Zhang ${ }^{\dagger}$ and Dong-Lin Sun
}

\begin{abstract}
Background: Solid pseudopapillary tumors (SPTS) of the pancreas are a rare neoplasm. There are few reports of laparoscopic central pancreatectomies (LCPS) for SPT of the pancreas. The objective of this study was to evaluate the feasibility, safety and long-term outcome of LCP based on a series of SPT patients.

Methods: This retrospective study included ten patients who underwent LCP between 2009 and 2013. Clinical characteristics and intra- and postoperative data were retrospectively analyzed. A follow-up of at least 3 months was available for all patients.

Results: All procedures were successfully performed laparoscopically, and no patient required intraoperative blood transfusion. The median operative time was $271 \mathrm{~min}$ (range 250 to $310 \mathrm{~min}$ ) and the median loss of blood was 104 $\mathrm{ml}$ (range 80 to $150 \mathrm{ml}$ ). The mean tumor size was $51 \mathrm{~mm}$ (range 38 to $62 \mathrm{~mm}$ ). All patients underwent complete resection with negative surgical margin. An average of 5.8 lymph nodes were resected without metastases. The median first flatus time was 2 days, and the median starting time for diet was 3 days. The median postoperative hospital stay was 13 days (range 10 to 23 days). Morbidity was 20\%. The median follow-up was 22.9 months (range 3 to 48 months), at which point all patients were alive with no recurrence. None of the patients developed exocrine or endocrine insufficiency. No hospital mortalities occurred in our patient group.
\end{abstract}

Conclusions: LCP is a safe and effective technique for resecting SPT of the neck and proximal body of the pancreas while preserving pancreatic endocrine and exocrine function, and the spleen.

Keywords: Solid pseudopapillary tumor, Pancreatic tumor, Laparoscopic central pancreatectomy

\section{Background}

Solid pseudopapillary tumors (SPTs) are a rare clinical entity, representing $1 \%$ to $2 \%$ of all primary exocrine tumors of the pancreas; more than $80 \%$ of patients are female [1]. SPT is of unclear histopathogenesis, and lowgrade malignancy, malignant degeneration and lymph node metastasis rarely occur [2]. Surgical resection of this tumor can result in long-term survival. Laparoscopic resection of the pancreas was initially described in the medical literature in the early 1990s. The first laparoscopic pancreatoduodenectomy was performed in 1994, and the first distal pancreatectomy was performed in

\footnotetext{
*Correspondence: tomuer@126.com

${ }^{\dagger}$ Equal contributors

Department of Hepatobiliary Surgery, The Third Affiliated Hospital of Soochow University, Changzhou 213003, China
}

$1996[3,4]$. However, patients who require central pancreatectomy are still being treated with the open approach or with laparoscopic distal pancreatectomy. Central pancreatectomy is an alternative technique for benign or low-grade malignant tumors of the neck of the pancreas. This pancreas-sparing technique was developed to avoid exocrine and/or endocrine insufficiency, which could be detrimental to the patient's quality of life, especially for benign or low-grade malignant neoplasms.

Although laparoscopic central pancreatectomy (LCP) is thought to be a function-preserving and minimally invasive pancreatectomy, due to the difficulty of pancreaticoenteric reconstruction, LCP has been slow to gain popularity. In an attempt to define the role and the efficacy of minimally invasive surgery in the treatment 
of SPT of the pancreas better, we therefore describe a complete LCP.

\section{Methods}

We undertook a retrospective cohort study of patients treated for SPT in our institution between February 2009 and December $2013(n=15)$. Of the patients, $66.6 \%(10 / 15)$ were treated using LCP, and the other five patients underwent a laparoscopic distal pancreatectomy. Descriptive data were collected. Preoperative variables include age, gender and indication for surgery. Pancreatic fistula, delayed gastric emptying and postpancreatectomy hemorrhage were defined according to the International Study Group of Pancreatic Surgery definitions [5-7]. Data collected included patient characteristics, operative details, morbidity and mortality, postoperative hospital stay, pathological findings and follow-up results. Oncologic outcomes were analyzed for all patients, and the data includes tumor size (maximum dimension in centimeters), total number of lymph nodes, number of positive lymph nodes and margin status. The fasting blood glucose level (normal $\leq 110 \mathrm{mg} / \mathrm{dL}$ ) was used to evaluate the pancreatic endocrine function. A clinical evaluation was used to assess the pancreatic exocrine function. Patients with diarrhea, weight loss and fatty stools were considered to have pancreatic exocrine insufficiency. Ethics committee of the third affiliated hospital of Soochow University approval and informed consent from the patients were obtained to perform LCP.

\section{Operative technique}

The LCP was performed with the patient in the supine and $30^{\circ}$ anti-Trendelenburg position with the surgeon standing between the patient's legs. Five trocars (three 5$\mathrm{mm}$ and two 10-mm trocars) were inserted into the upper abdominal quadrant. We used a supra-umbilical cutdown to establish pneumoperitoneum, with a $5-\mathrm{mm}$ port and a 10-mm port in the left upper and left flank quadrants, and two 5-mm ports in the right upper and right flank quadrants (Figure 1). We find such port placements are ergonomically good and allow adequate exposure. Under pneumoperitoneum, the gastrocolic ligament was divided to give access to the lesser sac using a Harmonic scalpel (Harmonic Ace; Ethicon Endo-Surgery, Cincinnati, OH, USA). The inferior border of the pancreas was dissected carefully using a blunt instrument to create a tunnel and expose the portal vein. The superior border of the pancreas was then dissected, and a tape was passed around

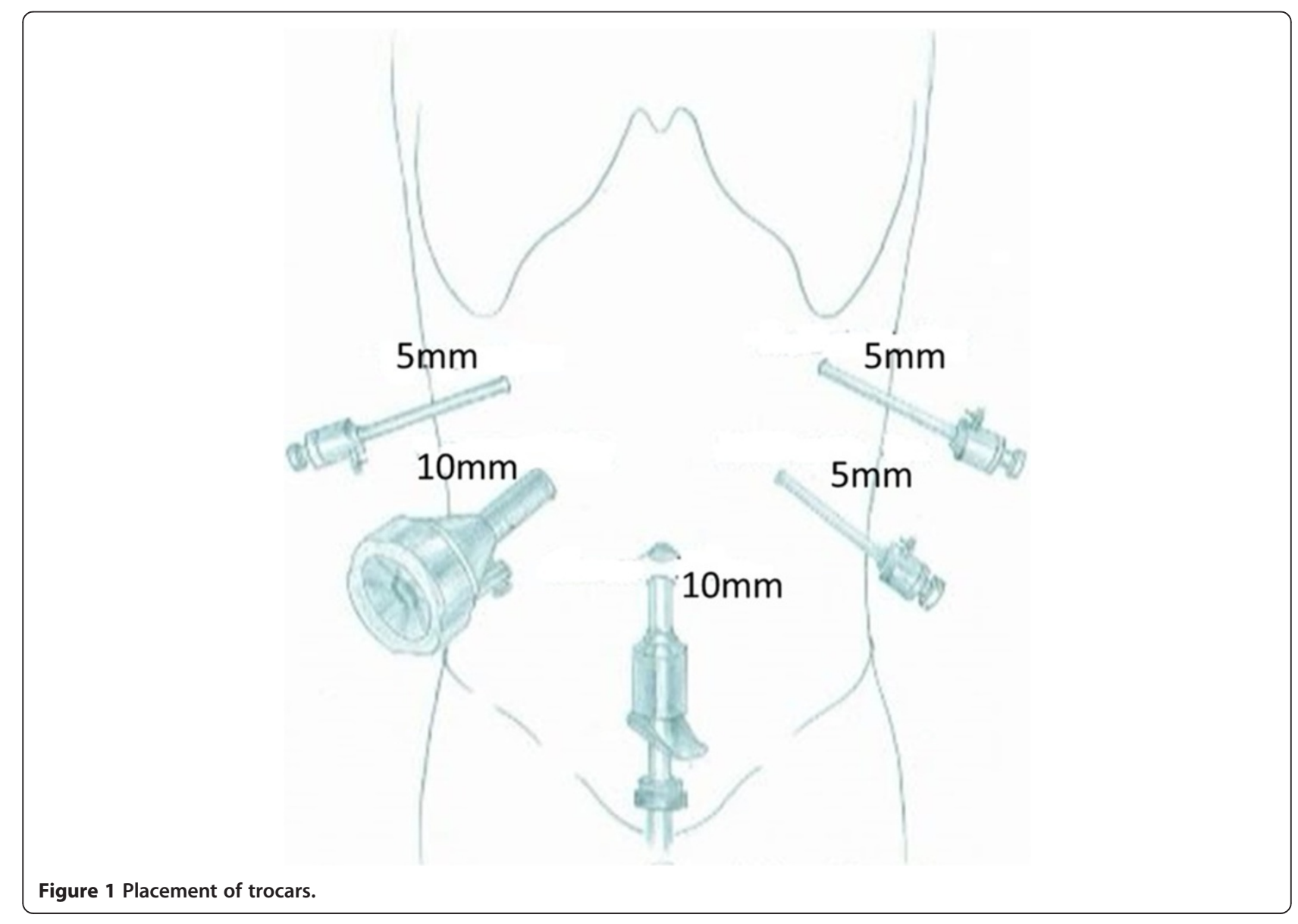


the neck of the pancreas. The next step was to dissect the proximal and distal parts of the neck of the pancreas. This can be achieved by removing the lymph nodes along the hepatic, the gastroduodenal and the splenic arteries. At this point, the splenic vessels and portal vein were completely dissected free from the pancreatic neck. The pancreas was transected with an endoscopic linear stapler (Endocutter 60 stapler, white or blue cartridge; Ethicon Endo-Surgery, Cincinnati, OH, USA) on the right side of the tumor followed by transection of the distal pancreas (Figure 2). The LCP was now complete. The surgical specimen was put inside a plastic bag and removed through the umbilical port. The specimen was examined, and frozen sections were used to evaluate the surgical margins.

After completing the pancreatic resection, a Roux-en$\mathrm{Y}$ jejunal loop was prepared. The jejunum was identified and divided using a stapler, $40 \mathrm{~cm}$ from the Treitz ligament. An end-to-side pancreatojejunostomy was then performed. A row of 3-0 coated polyglactin 910 sutures (Vicryl"; Ethicon Products, Johnson \& Johnson, Somerville, NJ, USA) with interrupted stitches was placed between the jejunal serosa and the posterior side of the pancreatic capsule for apposition. The jejunum was opened with a Harmonic scalpel, suitable for a distal pancreatic stump. The posterior layer was performed with a continuous or interrupted 3-0 Vicryl suture between the pancreas (parenchyma and capsule) and the full thickness of the jejunum. The anterior layer was performed in the same way as the posterior layer (Figure 3). Finally, a sideto-side jejunojejunostomy was performed with an endoscopic linear stapler (Endocutter 60 stapler, white cartridge). The abdominal cavity was reviewed and drained.

\section{Results}

LCP was performed successfully for all the patients. The splenic vessels and the spleen were preserved in all patients. Perioperative data are shown in Table 1. Their median age was 44.6 years (range 35 to 57 years). Eight patients were female and two male. One patient was admitted because of epigastric pain for 1 week; the others were found by chance during routine physical exams, and were asymptomatic. The median operative time was $271 \mathrm{~min}$ (range 250 to $310 \mathrm{~min}$ ) and the median loss of blood was $104 \mathrm{ml}$ (range 80 to $150 \mathrm{ml}$ ). The mean tumor size was $51 \mathrm{~mm}$ (range 38 to $62 \mathrm{~mm}$ ). All patients received complete resection with a negative surgical margin. An average number of 5.8 lymph nodes were resected without metastases. The median first flatus time was 2 days, and median starting time for diet was 3 days. The median postoperative hospital stay was 13 days (range 10 to 23 days). Two patients experienced a postoperative pancreatic fistula (grade A), which was managed conservatively and ultimately cured, and the drainage tubes were removed on postoperative days 17 and 20 , respectively. The hospital stay for these patients was 20 days and 23 days, respectively. The other patients recovered well after surgery. The median follow-up was 22.9 ( 3 to 48 ) months at which point all patients were alive with no recurrence. None of the patients developed exocrine or endocrine insufficiency. No hospital mortalities occurred in our patient group.

\section{Discussion}

Laparoscopic pancreatic surgery has undergone significant development in the last few years. The majority of

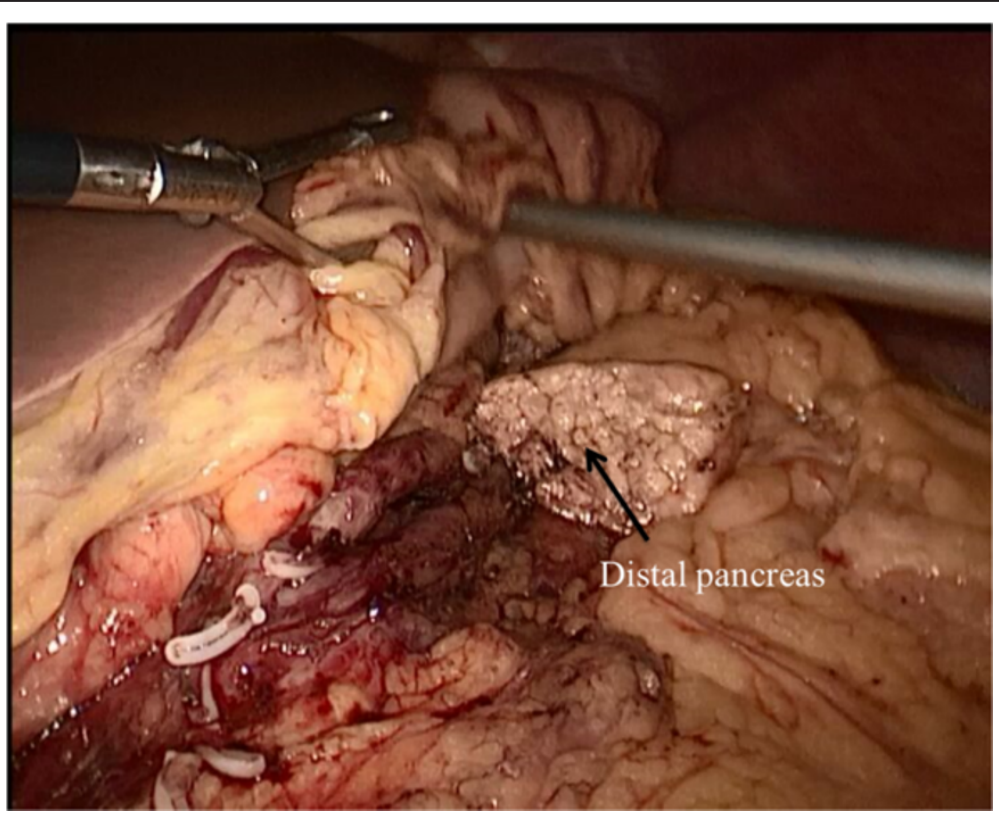

Figure 2 Pancreas dissection and transection performed by laparoscopic central pancreatectomy. 


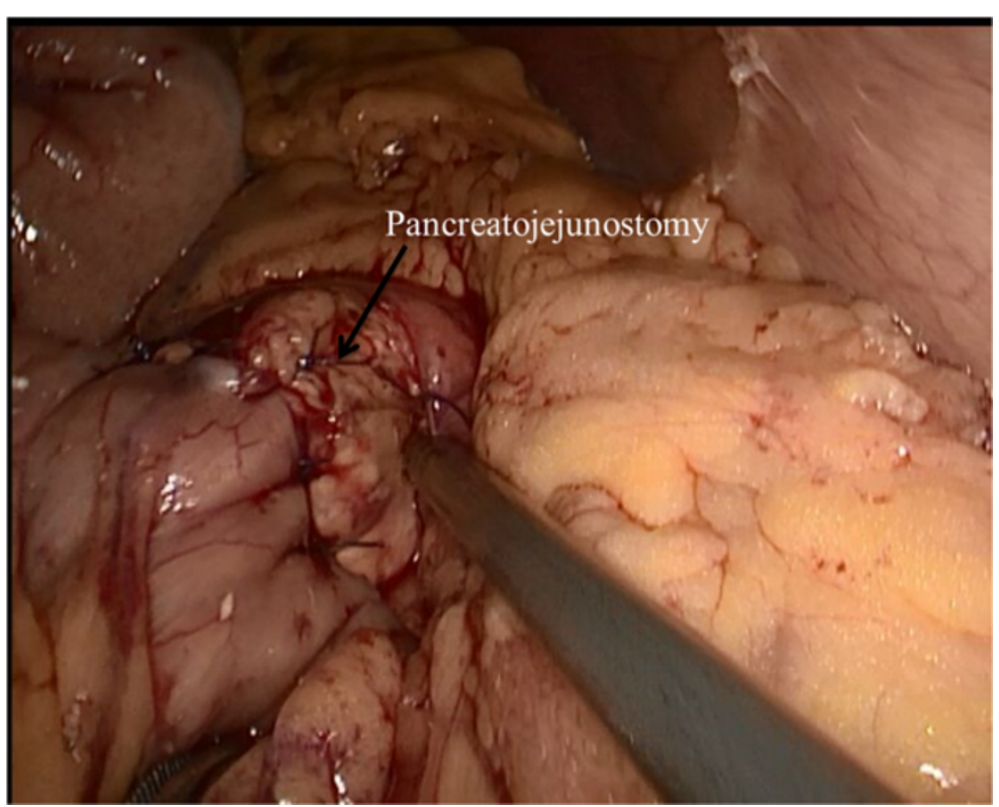

Figure 3 Pancreaticojejunostomy.

procedures are left pancreatectomy and enucleations [8-10]. More complex pancreatic resections such as pancreatoduodenectomies, resections of the uncinate process of the pancreas and central pancreatectomies are performed routinely in very few centers $[11,12]$.

The first surgical resection of a pancreatic SPT was performed in 1970 and the first laparoscopic SPT resection was in 2003 [13,14]. The first series of laparoscopic SPT resection (ten cases) was published by Cavallini et al. [15] in 2011. However, there have been few reports of LCP for SPT of the pancreas. Most of these articles are case reports and small series. The two largest series of LCP, with six and nine cases, respectively, reported morbidity rates of $33.3 \%$ and $33.3 \%$ with pancreatic fistula rates of $33.3 \%$ and $22.2 \%$, respectively, with no mortality [16,17]. A review of 512 patients from 21 series who underwent an open central pancreatectomy reported an overall morbidity rate of $41 \%$ (range $13 \%$ to $62 \%$ ), a pancreatic fistula rate of $27 \%$ (range $0 \%$ to $62 \%$ ) and a reoperation rate of $4 \%$ (range $0 \%$ to $21 \%$ ) [18]. Our series with ten cases had a morbidity rate of $20 \%$ (two cases of a pancreatic fistula), similar to what has been reported. In a comparative study, the outcomes after a central pancreatectomy were compared with a control group that underwent extended left pancreatectomy for neoplasms in the mid pancreas [19]. After a median

Table 1 Surgery-related information and postoperative outcomes

\begin{tabular}{|c|c|c|c|c|c|c|c|c|c|}
\hline Case & $\begin{array}{l}\text { Age/ } \\
\text { gender }\end{array}$ & $\begin{array}{l}\text { Operative } \\
\text { time (min) }\end{array}$ & $\begin{array}{l}\text { Blood } \\
\text { loss (ml) }\end{array}$ & $\begin{array}{l}\text { Postoperative } \\
\text { complication }\end{array}$ & $\begin{array}{l}\text { Hospital } \\
\text { stay (days) }\end{array}$ & $\begin{array}{l}\text { Tumor size } \\
\text { (mm) }\end{array}$ & $\begin{array}{l}\text { Lymph } \\
\text { nodes }\end{array}$ & $\begin{array}{l}\text { Follow-up } \\
\text { (months) }\end{array}$ & $\begin{array}{l}\text { Exocrine or endocrine } \\
\text { insufficiency }\end{array}$ \\
\hline 1 & $42 / F$ & 250 & 100 & - & 10 & 48 & 5 & 28 & None \\
\hline 2 & $35 / F$ & 280 & 110 & - & 10 & 51 & 6 & 36 & None \\
\hline 3 & $43 / F$ & 240 & 90 & - & 11 & 50 & 5 & 48 & None \\
\hline 4 & $40 / F$ & 300 & 120 & Pancreatic fistula & 20 & 60 & 7 & 12 & None \\
\hline 5 & $52 / F$ & 270 & 90 & - & 10 & 54 & 6 & 30 & None \\
\hline 6 & $57 / F$ & 260 & 100 & - & 12 & 55 & 5 & 30 & None \\
\hline 7 & 44/F & 260 & 90 & - & 11 & 50 & 6 & 24 & None \\
\hline 8 & $45 / M$ & 290 & 110 & - & 12 & 38 & 5 & 6 & None \\
\hline 9 & $40 / F$ & 250 & 80 & - & 12 & 42 & 6 & 3 & None \\
\hline 10 & $48 / M$ & 310 & 150 & Pancreatic fistula & 23 & 62 & 7 & 12 & None \\
\hline
\end{tabular}

F, female; $M$, male. 
follow-up of 54 months, the incidences of endocrine and exocrine insufficiency after the central pancreatectomy were $4 \%$ and $5 \%$, respectively, compared to $38 \%$ and $15.6 \%$ in patients who underwent an extended distal pancreatectomy. In this study, we have not observed any recurrence or pancreatic endocrine or exocrine insufficiency.

Laparoscopic resection of the neck of the pancreas or of any segment in the middle of the pancreas is not difficult. However, it entails reconstruction of the main pancreatic duct, which may be difficult and sometimes hazardous laparoscopically. The popularity of laparoscopic left pancreatectomy has certainly reduced the number of patients undergoing LCP. However, this is at the expense of the endocrine and exocrine deficiency that an extended left pancreatectomy may produce. For benign or low-grade neoplasms, a left pancreatectomy may remove too much of the functioning pancreatic parenchyma. Due to this, for cases with a tumor in the neck of the pancreas, our procedure of choice is a central pancreatectomy with Roux-en-Y pancreatojejunostomy. The management for a distal pancreas can be pancreatogastrostomy or Roux-en-Y pancreatojejunostomy. Pancreatogastrostomy is easier and faster, but it may delay oral feeding and it prolongs the length of stay. Pancreatojejunostomy is a more complex reconstruction, but has better long-term outcomes in terms of endocrine and exocrine function. As central pancreatectomy is indicated in patients with an expected long survival, some authors consider pancreatojejunostomy as the best management for the distal pancreas after central pancreatectomy. We also prefer reconstruction with Roux-en-Y pancreatojejunostomy.

Depending on whether the duct of Wirsung could be identified, we used two methods to accomplish the pancreaticojejunal reconstruction: end-to-side or duct-tomucosa pancreaticojejunal. If the diameter of the duct of Wirsung is larger than $5 \mathrm{~mm}$, duct-to-mucosa pancreaticojejunal is easier to execute. In our series, all patients had an undilated duct of Wirsung, which is difficult to identify. Therefore, end-to-side pancreaticojejunal seems to be easier and faster. A comparison between duct-tomucosa and end-to-side pancreaticojejunal reconstruction after pancreaticoduodenectomy revealed no significant differences in the rate of complications [20]. In our study, an end-to-side pancreaticojejunal was used to accomplish the pancreaticojejunal reconstruction and we had a pancreatic fistula rate of $20 \%$. A recent comparative study has shown that division of the pancreatic parenchyma with vascular cartridges resulted in a significantly lower fistula rate compared with standard cartridges [21]. It is still unclear if the use of staple-line reinforcement reduces the risk of a pancreatic fistula [22]. The limitations of this study were its retrospective design and low number of patients. These problems can be overcome only by a large, prospective randomized trial, which would be difficult to accomplish owing to the infrequent diagnosis of patients with SPT of the pancreas.

\section{Conclusions}

In conclusion, LCP is a safe and effective technique for resecting SPT of the neck and proximal body of the pancreas while preserving pancreatic endocrine and exocrine function, and the spleen. A minimally invasive approach ensures adequate treatment despite requiring the expertise of highly skilled laparoscopic surgeons.

Competing interests

The authors declare that they have no competing interests.

\section{Authors' contributions}

YZ and X-MC drafted and revised the manuscript. D-LS were responsible for acquisition and interpretation of data. All authors read and approved the final manuscript.

\section{Acknowledgements}

The authors thank Sheng yong Liu for language editing.

Received: 16 April 2014 Accepted: 1 October 2014

Published: 13 October 2014

\section{References}

1. Mao C, Guvendi M, Domenico DR, Kim K, Thomford NR, Howard JM: Papillary cystic and solid tumors of the pancreas: a pancreatic embryonic tumor? Studies of three cases and cumulative review of the world's literature. Surgery 1995, 118:821-828.

2. Papavramidis T, Papavramidis S: Solid pseudopapillary tumors of the pancreas: review of 718 patients reported in English literature. J Am Coll Surg 2005, 200:965-972.

3. Gagner M, Pomp A: Laparoscopic pylorus-preserving pancreatoduodenectomy. Surg Endosc 1994, 8:408-410.

4. Cuschieri A, Jakimowicz JJ, Van Spreeuwel J: Laparoscopic distal 70\% pancreatectomy and splenectomy for chronic pancreatitis. Ann Surg 1996, 223:280-285.

5. Bassi C, Dervenis C, Butturini G, Fingerhut A, Yeo C, Izbicki J, Neoptolemos J, Sarr M, Traverso W, Buchler M: Postoperative pancreatic fistula: an international study group (ISGPF) definition. Surgery 2005, 138:8-13.

6. Wente MN, Bassi C, Dervenis C, Fingerhut A, Gouma DJ, Izbicki JR, Neoptolemos JP, Padbury RT, Sarr MG, Traverso LW, Yeo CJ, Büchler MW: Delayed gastric emptying (DGE) after pancreatic surgery: a suggested definition by the International Study Group of Pancreatic Surgery (ISGPS). Surgery 2007, 142:761-768.

7. Wente MN, Veit JA, Bassi C, Dervenis C, Fingerhut A, Gouma DJ, Izbicki JR, Neoptolemos JP, Padbury RT, Sarr MG, Yeo CJ, Büchler MW: Postpancreatectomy haemorrhage (PPH): an International Study Group of Pancreatic Surgery (ISGPS) definition. Surgery 2007, 142:20-25.

8. Gumbs AA, Rodriguez Rivera AM, Milone L, Hoffman JP: Laparoscopic pancreatoduodenectomy: a review of 285 published cases. Ann Surg Oncol 2011, 18:1335-1341.

9. Jayaraman S, Gonen M, Brennan MF, D'Angelica MI, DeMatteo RP, Fong $Y$, Jarnagin WR, Allen PJ: Laparoscopic distal pancreatectomy: evolution of a technique at a single institution. J Am Coll Surg 2010, 211:503-509.

10. Kneuertz PJ, Patel SH, Chu CK, Fisher SB, Maithel SK, Sarmiento JM, Weber SM, Staley CA, Kooby DA: Laparoscopic distal pancreatectomy: trends and lessons learned through an 11-year experience. J Am Coll Surg 2012, 215:167-176.

11. Rotellar F, Pardo F, Benito A, Martí-Cruchaga P, Zozaya G, Cienfuegos JA: Laparoscopic resection of the uncinate process of the pancreas: the inframesocolic approach and hanging maneuver of the mesenteric root. Surg Endosc 2011, 25:3426-3427.

12. Schraibman V, Goldman SM, Ardengh JC, Goldenberg A, Lobo E, Linhares MM, Gonzales AM, Abdala N, Abud TG, Ajzen SA, Jackowsky A, Szejnfeld J: New trends in diffusion-weighted magnetic resonance imaging as a tool 
in differentiation of serous cystadenoma and mucinous cystic tumor: a prospective study. Pancreatology 2011, 11:43-51.

13. Hamoudi AB, Misugi K, Grosfeld JL, Reiner CB: Papillary epithelial neoplasm of pancreas in a child: report of a case with electron microscopy. Cancer 1970, 26:1126-1134.

14. Carricaburu E, Enezian G, Bonnard A, Berrebi D, Belarbi N, Huot O, Aigrain Y, De Lagausie P: Laparoscopic distal pancreatectomy for Frantz's tumor in a child. Surg Endosc 2003, 17:2028-2031.

15. Cavallini A, Butturini G, Daskalaki D, Salvia R, Melotti G, Piccoli M, Bassi C, Pederzoli P: Laparoscopic pancreatectomy for solid pseudo-papillary tumors of the pancreas is a suitable technique; our experience with long-term follow-up and review of the literature. Ann Surg Oncol 2011, 18:352-357.

16. Sa Cunha A, Rault A, Beau C, Collet D, Masson B: Laparoscopic central pancreatectomy: single-institution experience of 6 patients. Surgery 2007, 142:405-409.

17. Rotellar F, Pardo F, Montiel C, Benito A, Regueira FM, Poveda I, MartíCruchaga P, Cienfuegos JA: Totally laparoscopic Roux-en-Y duct-tomucosa pancreaticojejunostomy after middle pancreatectomy: a consecutive nine-case series at a single institution. Ann Surg 2008, 247:938-944.

18. Shikano T, Nakao A, Kodera Y, Yamada S, Fujii T, Sugimoto H, Kanazumi N, Nomoto S, Takeda S: Middle pancreatectomy: safety and long-term results. Surgery 2010, 147:21-29.

19. Crippa S, Bassi C, Warshaw AL, Falconi M, Partelli S, Thayer SP, Pederzoli P, Fernández-del CC: Middle pancreatectomy: indications, short- and longterm operative outcomes. Ann Surg 2007, 246:69-76.

20. Bassi C, Falconi M, Molinari E, Mantovani W, Butturini G, Gumbs AA, Salvia R, Pederzoli P: Duct-to-mucosa versus end-to-side pancreaticojejunostomy reconstruction after pancreaticoduodenectomy: results of a prospective randomized trial. Surgery 2003, 134:766-771.

21. Sepesi B, Moalem J, Galka E, Salzman P, Schoeniger LO: The influence of staple size on fistula formation following distal pancreatectomy. J Gastrointest Surg 2012, 16:267-274.

22. Subhedar PD, Patel SH, Kneuertz PJ, Maithel SK, Staley CA, Sarmiento JM Galloway JR, Kooby DA: Risk factors for pancreatic fistula after stapled gland transection. Am Surg 2011, 77:965-970.

doi:10.1186/1477-7819-12-312

Cite this article as: Chen et al.: Laparoscopic central pancreatectomy for solid pseudopapillary tumors of the pancreas: our experience with ten cases. World Journal of Surgical Oncology 2014 12:312.

\section{Submit your next manuscript to BioMed Central and take full advantage of:}

- Convenient online submission

- Thorough peer review

- No space constraints or color figure charges

- Immediate publication on acceptance

- Inclusion in PubMed, CAS, Scopus and Google Scholar

- Research which is freely available for redistribution 